\title{
Planetary pressures
}

\author{
Jean Venables
}

The Future is not what it used to be!

Despite all our computer models of future climate scenarios and predicted effects, they are only possible scenarios. We live at a time of instability - financial, economic, social, and climate which is making unprecedented and increasing demands on our planet. But instability can be a great time to trigger journeys in new directions, so what might the journey over the next fifty years look like?

The demands on our planet have been measured by eco-footprinting. If everyone on the planet were to consume and waste resources at the same level as UK citizens, we would need three and a half planets. Last time I looked, we just had one. So; whilst our inventiveness, creativity and technology will help, peoples' expectations and behaviours must change to adapt to one planet living, to a low carbon economy and low carbon living, to the climate change we have already, and to the climate change to come. How we respond will be crucial to survival; not of the planet, but of the human race. The effectiveness of our mitigation of the cause of climate change will govern how much adaptation will be necessary to adjust to rising temperatures, sea levels and wind speeds.

One important recent action has perhaps set a path for how to plan for and implement adaptation strategies in the face of uncertainty. The Thames Estuary 2100 Project sought to identify how to manage the flood risks to London and the Thames Estuary over the next 100 years. The outputs plotted the actions to take against possible sea level rises, and related the trigger times for starting intervention measures to the trajectory of observed sea level rise in coming years. This approach can be replicated not only in other major estuaries of the world, but for other types of infrastructure that will need to be upgraded to cope with the effects of climate change. The TE2100 Project outcomes also emphasised the vital need to maintain our current flood defences, which is indeed good advice for all of our infrastructure, not just flood defence assets.

Another major influencer on how our infrastructure will help us cope, or not, over the next fifty years is the organisational structures we have created for our major resources and associated utilities. Our separation of different functional parts of our support systems is not helpful. Take water as an example; we have public and private bodies dealing with water supply, wastewater treatment, the quality of the water environment, some on catchment boundaries, some on Local Authority

How to cite this book chapter:

Venables, J. 2013. Planetary pressures. In: Bell, S and Paskins, J. (eds.) Imagining the Future City: London 2062. Pp. 45-47. London: Ubiquity Press. DOI: http://dx.doi.org/10.5334/bag.f 
boundaries (both county and local), with different legislative regimes. Decision boundaries are not always drawn in the interests of the planet, the water system or society, but in the interests of the organisations involved.

Will we have, by 2062, an organisation responsible for the water cycle? I do hope so, but I fear not. Perverse investment incentives for water companies do not help. Rainwater is too valuable a resource to end up in sewers. So we need to have created separated sewer systems to capture the water we need for not only potable supplies but for energy production, for growing food and for environmental needs.

Currently, the world wastes one third of the food grown, despite hunger in many places across the UK and across the globe. In fifty years' time, will we waste less? Or will we grow food in laboratories to meet our needs? That would be a great contrast to the rationing of food and minimal wastage in the UK in the 1950s. Will we revert to rationing to reduce waste? Will wasting food become as socially unacceptable as drinking and driving and smoking in public places has now become?

Energy supply, especially of electricity, underpins our current way of life - heating, lighting, air conditioning, transport, and especially communications and control equipment. And much of that energy is still hydrocarbon based, and therefore emits $\mathrm{CO}_{2}$ and other greenhouse gas emissions. If we are to create a low carbon economy and enable low carbon living, then we must use hydrocarbon based energy wisely: to create lower carbon sources, and to make more energy efficient buildings, vehicles and infrastructure. Perhaps most crucially, we need to attune the expectations and behaviours of populations worldwide to the imperative of low carbon living. Two crucial technologies needed to effect the change are dramatic developments in energy efficiency and battery technology, to change our production, delivery, storage and usage of electrical energy.

How will we make our journey to 2062 ? A look back to the science fiction fifty years ago shows that - through human creativity and innovation - many of those fifty-year-old science fiction ideas are now a reality. Developments from the past fifty years in my lifetime include computers; space exploration; communication methods - small and very smart mobile phones, emails etc; food - from rationing to plenty to needless waste; and extensive and cheap travel - the list is extensive.

Although some of the last fifty years of innovation and inventions are in part causes of our current difficulties, many have helped enormously to improve quality of life and the environment. So I think we can and should be hopeful that another fifty years of that human creativity and innovation, this time also spurred on by the climate, carbon and environmental imperatives, can give us the necessary technology developments, whether part of current science fiction thinking or not. Whether better governance and adjusted human expectations and attitudes can be delivered in the same period, we may be less optimistic; but we should remain determined to press for change for the greater good.

Children born in the first decade of the twentieth century will be in their fifties and sixties in 2062, 100 years after Rachel Carson wrote Silent Spring. We wonder what will life be like for them, but also recognise that they will have had at least 25 years of their own careers to shape their own future. Let us hope that we are able to inspire both the current and next generations to reverse the excesses of recent decades, restore the environmental damages those excesses have wrought, and create the necessary sustaining technologies and political governance systems. 


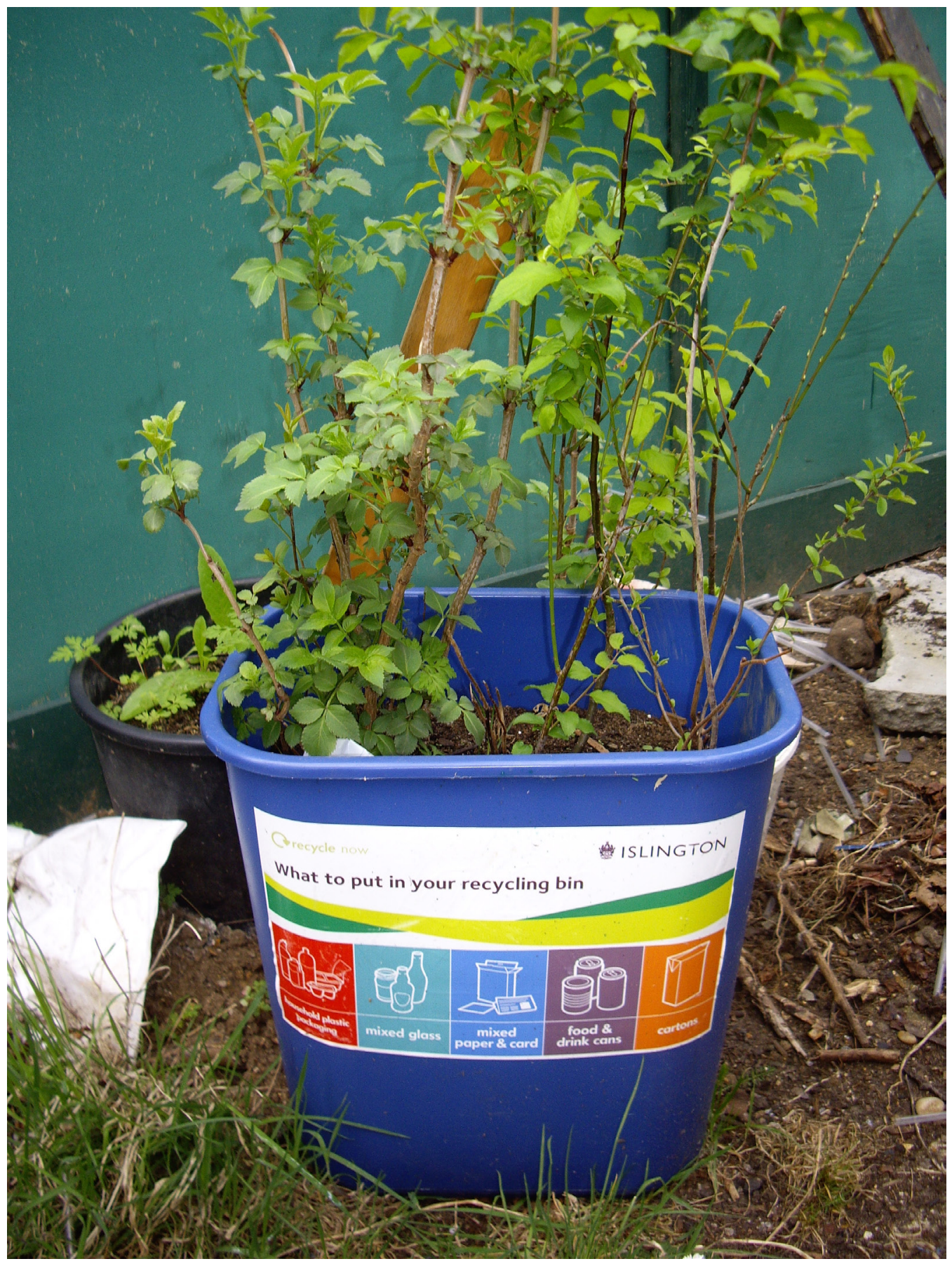

